\title{
Corrosion and tribocorrosion behaviour of $\beta$-type Ti-Nb and Ti-Mo surfaces designed by diffusion treatments for biomedical applications
}

\author{
J. Ureña ${ }^{\mathrm{a}, *}$, S. Tsipas ${ }^{\mathrm{a}}$, A.M. Pinto ${ }^{\mathrm{b}}$, F. Toptan ${ }^{\mathrm{b}}$, E. Gordo ${ }^{\mathrm{a}}$, A. Jiménez-Morales ${ }^{\mathrm{a}}$

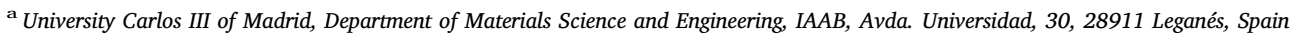 \\ b CMEMS-UMINHO - Center of MicroElectroMechanical Systems - Universidade do Minho, Azurém, 4800-058 Guimarães, Portugal
}

\section{A R T I C L E I N F O}

\section{Keywords:}

$\beta$-Gradient titanium

Powder technology

$\mathrm{Nb}$ and Mo surface treatments

Corrosion

Tribocorrosion

\begin{abstract}
A B S T R A C T
Corrosion and tribocorrosion behaviour of modified Ti surfaces through thermochemical treatments has been studied. Electrochemical Impedance Spectroscopy (EIS) and reciprocating sliding tests using a ball-on-plate tribometer under $1 \mathrm{~N}$ load and alumina as counter-material were used to evaluate the influence of $\mathrm{Nb}$ and $\mathrm{Mo}$ on titanium corrosion and tribocorrosion properties.

Ti-Nb and Ti-Mo surfaces exhibited better anticorrosive properties than CP-titanium. Under tribological action the modified Ti surfaces showed similar coefficient of friction and lower tendency to corrosion compared to $\mathrm{CP}-\mathrm{Ti}$. Furthermore, $\mathrm{Nb}$ diffusion increased the repassivation rate with respect to Ti and Ti-Mo surfaces due to its stable passive film.
\end{abstract}

\section{Introduction}

In the search for new biomaterials with better performance for implants, stainless steel, cobalt-chromium alloys and titanium and its alloys are regarded to be the most important [1,2]. However, among these metallic biomaterials, Ti and its alloys are widely developed due to their excellent combination of properties and high corrosion resistance. Especially, $\beta$-Ti type alloys are the most promising ones due to their great corrosion resistance and low Young's modulus (55-90 GPa) with respect to stainless steel $(210 \mathrm{GPa})$ or cobalt alloys (240 $\mathrm{GPa}$ ) $[3,4]$. Corrosion behaviour is one of the main factors for the suitable biocompatibility of biomaterials, since, similar to wear, a poor corrosion resistance results in debris generation which may be soluble in blood or particulate debris accumulation in human tissues; provoking short term effects (inflammation and damage of cell tissue) or long term effects (toxicity and carcinogenetic response) [5,6]. Biocompatibility of the elements used in the design of a biomaterial plays an important role on debris generation. For instance, non-compatible metal ions like Fe, $\mathrm{Ni}, \mathrm{Cr}, \mathrm{Co}, \mathrm{Al}, \mathrm{V}$ lead to toxic reactions with adverse effects such as: damage of protein, DNA or lipids (with increased Fe amount); alteration of sugar levels in the blood (with increased $\mathrm{Cr}$ amount); toxicity reactions after 4-5 years (with increased Ni or Co amount), etc. [2].

The selection of a specific metal must be performed depending on its final biomedical application. For instance, Ti-6Al-4 V and Ti-6Al-7Nb covered with bone cement to give extra fixation to the femoral components can suffer from crevice corrosion, whereas Ti and its alloys are susceptible of pitting corrosion in elevated fluoride solutions used in dental cleaning $[7,8]$. This pitting corrosion is related to the formation of hydrated $\mathrm{Ti}$ oxides $\mathrm{Ti}(\mathrm{OH})_{2} \mathrm{~F}^{+}$, and salts such as $[\mathrm{TiF} 6]^{2-}, \mathrm{TiH}_{2}$, $\mathrm{Na}_{3} \mathrm{Ti}_{3} \mathrm{~F}_{14}, \mathrm{TiF}_{4}\left[\mathrm{TiF}_{6}\right]^{3-}$ in the presence of HF [9].

Furthermore, wear-related problems derived from synergistic wearcorrosion interactions also lead to swelling, pain and other drawbacks related to the tribocorrosion resistance of the implant material [10]. This synergism between the apparition of corrosion pits on surface from partial metallic ions dissolution due to wear during sliding becomes critical in an implant material [7]. Although the corrosion resistance of $\mathrm{Ti}$ alloys and especially Ti6Al4V is proven to be high, there are concerns with $\mathrm{Al}$ and $\mathrm{V}$ due to their possible long term cytotoxic effect on the human body. Moreover, in some alloys such as Ti-13.4Al-29Nb, the passive layer breakdown was associated to the high $\mathrm{Al}$ content [11].

Hence, the replacement of these elements with $\mathrm{Nb}$, Mo, Ta or $\mathrm{Zr}(\beta-$ stabilizing elements) is one of the alternatives to enhance the performance of biomedical Ti materials $[5,12]$. Surface treatments with niobium or molybdenum allow decrease in the elastic modulus of titanium as well as formation of stable oxides layers such as $\mathrm{Nb}_{2} \mathrm{O}_{5}$ in air or in tissue fluids. On the other hand, $\mathrm{Nb}$ not only increases the corrosion resistance of $\mathrm{Ti}$ with a fast repassivation rate but also exhibits excellent biocompatibility $[3,13]$.

Therefore, there is still the necessity of developing new $\beta$-Ti type multifunctional surfaces that accomplish the simultaneous

\footnotetext{
* Corresponding author.

E-mail addresses: jurena@pa.uc3m.es (J. Ureña), stsipas@ing.uc3m.es (S. Tsipas), anapinto@dem.uminho.pt (A.M. Pinto), ftoptan@dem.uminho.pt (F. Toptan), elena.gordo@uc3m.es (E. Gordo), toni@ing.uc3m.es (A. Jiménez-Morales).
} 
requirements of high corrosion resistance, wear and tribocorrosion properties maintaining a good biocompatibility. Recently, different Ti$\mathrm{Nb}$, Ti-Mo and Ti-Nb-Mo compositions have been studied, evaluating the effect of niobium or molybdenum content on the corrosion behaviour and obtaining the best corrosion resistance for a $\mathrm{Nb}$ content between 8-16\% [14]. The effect of a biofilm on coefficient of friction was also reported as beneficial for reducing the friction behaviour of titanium implants [15]. Another related study of the $\beta$-alloy Ti-13Nb-13Zr showed improved corrosion behaviour compared to the conventional alloys Ti6Al4V and Ti6Al7Nb. However, the tribocorrosion behaviour of the $\beta$-Ti alloys when they are under synergistic wear-corrosion interactions is more controversial and less comprehensive due to the lack of standard test conditions [10]. Generally, $\beta$-Ti alloys in SBF could lead to the formation of hydroxyapatite on surface together with the apparition of entrapped hydroxyapatite particles which can act as solid lubricants or cause three-body abrasion wear. This is the case of Ti-12Mo$6 \mathrm{Zr}-2 \mathrm{Fe}$ alloy and the binary systems $\mathrm{Ti}-45 \mathrm{Nb}$ and Ti-15Mo tested under $5 \mathrm{~N}$ and $200 \mathrm{~m}$ sliding distance in SBF conditions [16]. However, some $\beta$-Ti surfaces such as Ti-13Nb-13Zr or Ti-15Zr-7.5Mo exhibit similar tribocorrosion behaviour to the $\alpha-\beta$ Ti- $6 \mathrm{Al}-4 \mathrm{~V}$ or commercially pure $\mathrm{Ti}$ (CP-Ti) $[17,18]$. On the other hand, $\mathrm{TiN}$ or $\mathrm{Ti}_{2} \mathrm{~N}$ formation by nitriding surface treatments are among the methods that increase noticeably the wear and corrosion behaviour [2,19].

Dry sliding wear of conventional biomedical Ti alloys has been the focus of recent studies, nevertheless there is still relatively little knowledge of the corrosion and tribocorrosion properties of diffusionbased powder metallurgy Ti surfaces designed by thermo-chemical treatments. It is worth emphasizing that these Ti-Nb and Ti-Mo surfaces exhibit improved wear resistance [20] and positive cell-material response [21], [22]. Therefore, is also necessary to study corrosion and tribocorrosion behaviour of these materials before considering them for biomaterials. Thus, this work aims to report on the corrosion and tribocorrosion behaviour of powder metallurgy $\beta$-Ti surfaces designed through $\mathrm{Nb}$ and Mo diffusion treatments in comparison with the powder metallurgy cp-Ti biomaterial in $9 \mathrm{~g} / \mathrm{l} \mathrm{NaCl}$ solution.

\section{Experimental procedure}

\subsection{Materials}

Table 1 shows the design parameters used for the fabrication of the diffusion-based titanium surfaces together with their hardness and elastic modulus characteristics. $\beta$-type Ti-Nb and Ti-Mo surfaces were designed through surface modification of titanium substrates processed by powder metallurgy.

In this study, titanium substrates were fabricated from hydride-dehydride $(\mathrm{HDH})$ commercially pure titanium powder (CP-Ti grade 4) (GfE Metalle und Materialien GmbH, Germany) with particle size below

Table 1

Design parameters of the modified Ti surfaces. Hardness and elastic modulus values [24].

\begin{tabular}{|c|c|c|c|c|c|}
\hline \multirow[t]{2}{*}{ Materials } & \multicolumn{3}{|c|}{ Design parameters } & \multicolumn{2}{|c|}{ Mechanical properties } \\
\hline & Ti substrate & $\begin{array}{l}\text { Diffusion } \\
\text { element }\end{array}$ & $\begin{array}{l}\text { Diffusion } \\
\text { treatment }\end{array}$ & $\begin{array}{l}\text { Hardness } \\
(\mathrm{HV})\end{array}$ & $\begin{array}{l}\text { Elastic } \\
\text { modulus } \\
(\mathrm{GPa})\end{array}$ \\
\hline $\mathrm{Ti}$ & Sintered & - & - & $279 \pm 10$ & $105 \pm 3$ \\
\hline GreenTi-Nb & Green & $\mathrm{Nb}$ & Diffusion $^{\mathrm{a}}$ & $300 \pm 16$ & $54 \pm 5$ \\
\hline GreenTi-Mo & Green & Mo & Diffusion $^{a}$ & $370 \pm 17$ & $65 \pm 9$ \\
\hline Ti-Nb & Sintered & $\mathrm{Nb}$ & Diffusion $^{\mathrm{a}}$ & $320 \pm 14$ & $64 \pm 5$ \\
\hline Ti-Mo & Sintered & Mo & Diffusion $^{\mathrm{a}}$ & $430 \pm 21$ & $63 \pm 8$ \\
\hline $\mathrm{Ti}-\mathrm{Mo}_{\mathrm{NH} 4 \mathrm{Cl}}$ & Sintered & $\mathrm{Mo}+\mathrm{NH}_{4} \mathrm{Cl}$ & $\mathrm{TRD}^{\mathrm{b}}$ & $1025 \pm 25$ & $130 \pm 15$ \\
\hline
\end{tabular}

\footnotetext{
${ }^{\text {a }}$ In high vacuum $\left(10^{-5}\right.$ mbar $)$.

b Thermo-reactive diffusion (in Ar atmosphere with activating agent $\left(\mathrm{NH}_{4} \mathrm{Cl}\right)$ ).
}

to $75 \mu \mathrm{m}$. Once the powder metallurgy Ti substrates were obtained, the surface modification process was carried out varying the following parameters: state of the titanium substrate - green Ti (as-pressed) or sintered Ti substrates - and by adding an activating agent $\left(\mathrm{NH}_{4} \mathrm{Cl}\right)$. Therefore, three different diffusion routes were used: i) co-sintering + diffusion (in one single step), ii) diffusion treatment after sintering, and iii) thermo-reactive diffusion; as detailed elsewhere [23].

Micro-sized Mo and Nb powders of $1-2 \mu \mathrm{m}$ and $44 \mu \mathrm{m}$, respectively, were the $\beta$-stabilizing elements selected due to their beta-phase formation ability. The coated-titanium substrates were thermally-treated at $1100^{\circ} \mathrm{C}$ during $3 \mathrm{~h}$ in order to promote the element diffusion, with details of the deposition and processing procedure previously reported in [23]. Before tests, all samples were softly grinded by using a $1200 \#$ $\mathrm{SiC}$ emery paper in order to remove the rests of non-diffused coating. Then, since a lower surface roughness improves the tribological and corrosion properties [3], they were polished with $1 \mu \mathrm{m}$ alumina suspension. For comparison purposes, a polished sintered titanium substrate was chosen as a control sample. Microstructures and mechanical properties of the designed materials are reported in detailed in a previous work [24].

\subsection{Electrochemical measurements}

Electrochemical impedance spectroscopy (EIS) was selected to evaluate the corrosion behaviour of the modified $\mathrm{Ti}$ surfaces. Impedance and open circuit potential (OCP) measurements were performed in a $9 \mathrm{~g} / \mathrm{l}$ of $\mathrm{NaCl}$ solution through an Autolab potentiostat (PGSTAT302 N) in a frequency range from $10 \mathrm{mHz}$ to $10 \mathrm{KHz}$ at $\pm 10 \mathrm{mV}$ of amplitude of sinusoidal wave. For comparison purposes, the same electrolyte was selected for the tribocorrosion tests. A standard three-electrode electrochemical cell was employed with a volume of $20 \mathrm{ml}$ in which a platinum wire acted as counter electrode, an $\mathrm{Ag}$ / $\mathrm{AgCl}(\mathrm{KCl} 3 \mathrm{M})$ as reference electrode and a surface sample as the working electrode. Potential was measured based on the reference electrode whose potential relative to the standard hydrogen electrode (SHE) was $205 \mathrm{mV}$. Fig. 1 shows an arrangement of the electrochemical cell for the EIS tests and the routine used to make the electrochemical measurements.

ZView Version 3.5d software was used for the processing of the impedance data obtained and the results were fitted to the most similar equivalent circuit. All tests were repeated three times in order to obtain good reproducibility and validity in the results.

\subsection{Tribocorrosion tests}

Triboelectrochemical measurements were carried out in an electrochemical cell placed on a ball-on-plate-tribometer (CETR-UMT-2) where the working surface of the samples were the moving body and facing upwards against the static counter material $(10 \mathrm{~mm}$ diameter alumina ball, Ceratec). To avoid the complexity of physiological body fluids, a $9 \mathrm{~g} / \mathrm{l} \mathrm{NaCl}$ solution was selected as electrolyte as this is the major compound of Phosphate Buffered Saline (PBS) physiological solutions $[7,25]$.

Electrochemical measurements were performed at room temperature by using Voltalab PGZ 100 potentiostat. A two electrode set up was employed where a saturated calomel electrode (SCE) was the reference electrode and the samples -having an exposed area of $177 \mathrm{~mm}^{2}$ - the working electrode. Open circuit potential (OCP) was measured before, during and after sliding, while the sliding action was initiated once the values of OCP were stable in each test (approximately $1 \mathrm{~h}$ ). The tribological parameters for the tests were: $1 \mathrm{~N}$ normal load, $1 \mathrm{~Hz}$ of frequency, $10 \mathrm{~mm}$ of total stroke length and 1800 s sliding time. Fig. 2 shows an arrangement of the experimental tribocorrosion cell and the sequences of OCP and sliding. 


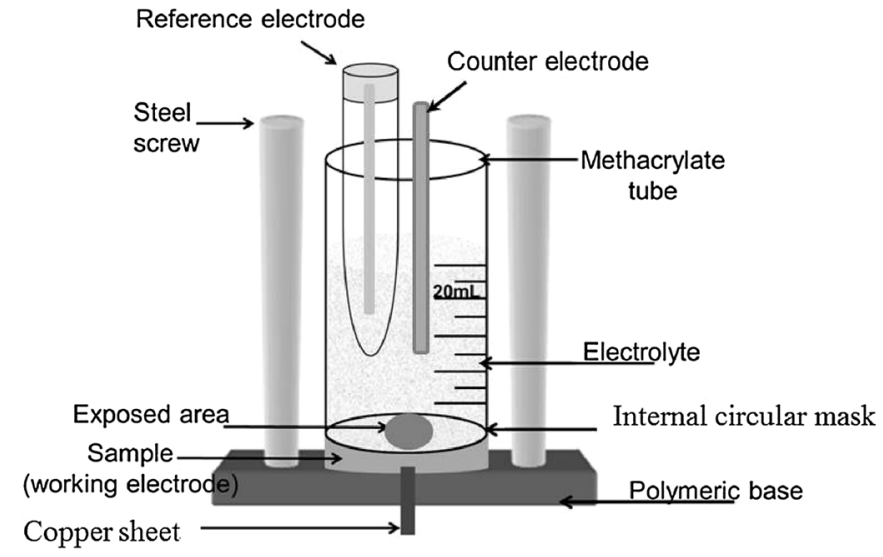

OCP (1)

EIS

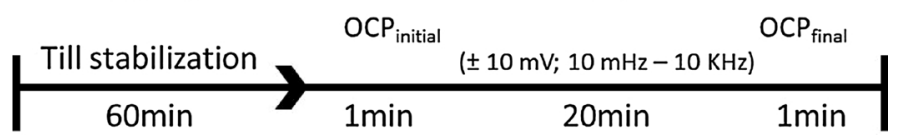

Fig. 1. Schematic view of the electrochemical cell for the EIS tests together with the followed routine.

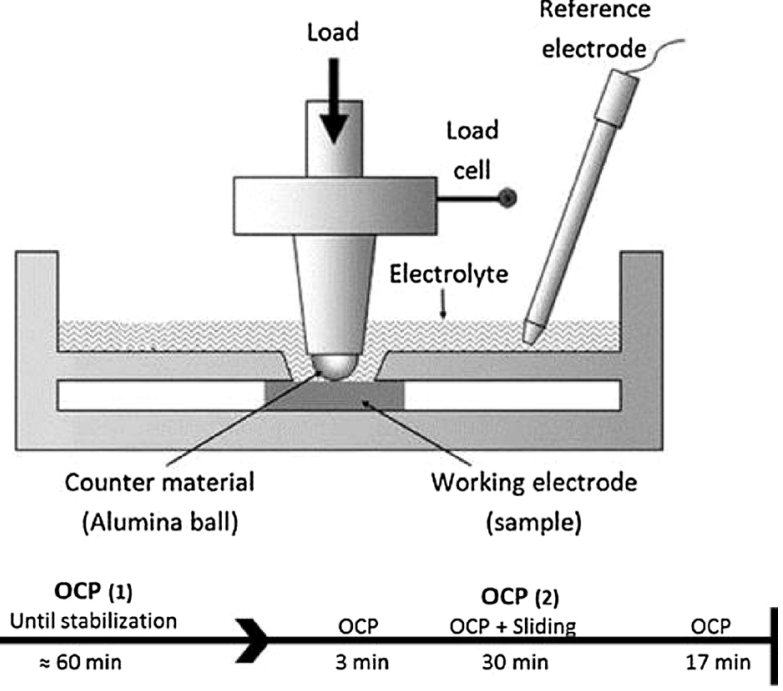

Fig. 2. Schematic view of the tribocorrosion experimental cell adapted from [26], and OCP and sliding sequences.

\subsection{Surface characterization}

After the tribocorrosion tests, samples were ultrasonically cleaned in propanol for $10 \mathrm{~min}$ followed by distilled water for $5 \mathrm{~min}$ and worn surfaces were characterized using SEM equipped with EDAX, energy dispersive X-ray spectroscopy (EDS). The wear tracks were measured in terms of width and depth by an optical profilometer (Olympus, DSX500, Opto-Digital Microscope). Wear volume was calculated as detailed in a previous work [20].

\section{Results and discussion}

\subsection{Electrochemical characterization: corrosion behaviour}

As examples of the evolution of the open circuit potential, Fig. 3 shows the OCP values for $\mathrm{CP}-\mathrm{Ti}$, Ti-Nb and Ti-Mo $\mathrm{NH}_{4 \mathrm{Cl}}$ during $1 \mathrm{~h}$ of immersion in saline solution. Since all of the modified samples exhibited quite similar $\mathrm{OCP}$ evolution, $\mathrm{Ti}-\mathrm{Nb}$ and $\mathrm{Ti}-\mathrm{Mo}_{\mathrm{NH} 4 \mathrm{Cl}}$ are displayed as examples of $\mathrm{Nb}$ and Mo diffusion, respectively. The modified

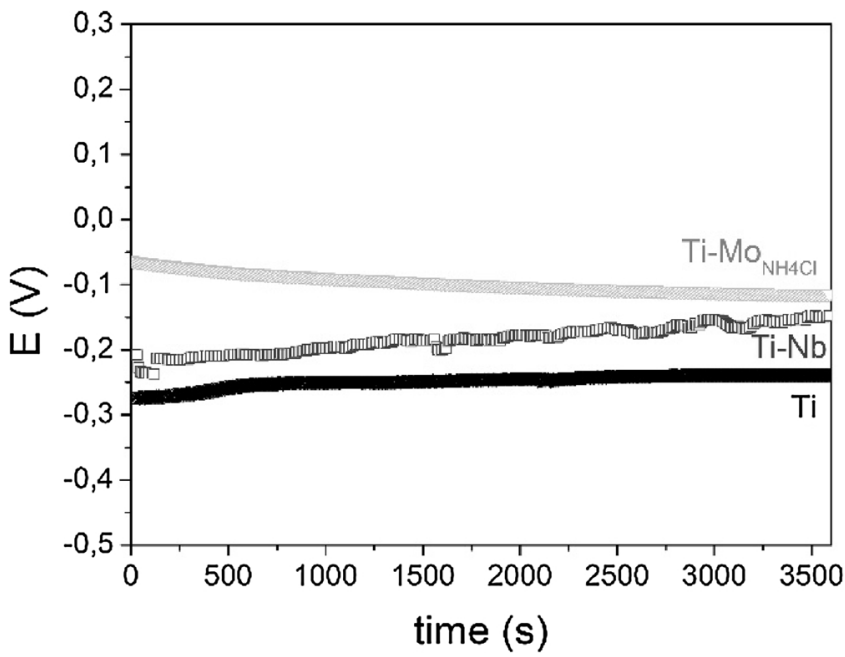

Fig. 3. Open-circuit potential evolution for $\mathrm{Ti}, \mathrm{Ti}-\mathrm{Nb}$ and $\mathrm{Ti}-\mathrm{Mo}_{\mathrm{NH} 4 \mathrm{Cl}}$ surfaces during $1 \mathrm{~h}$ of immersion in $9 \mathrm{~g} / \mathrm{l} \mathrm{NaCl}$ solution.

samples and CP-Ti material showed $\mathrm{E}_{\mathrm{oc}}$ values quasi-stationary at $1 \mathrm{~h}$ indicative of their stabilization. However, the tendency of the OCP values during the recorded time for $\mathrm{Ti}$ and $\mathrm{Ti}-\mathrm{Nb}$ was moving towards more positive values whereas that was not the case for Ti-Mo $\mathrm{NH}_{\mathrm{NCl}}$. This may be indicating that $\mathrm{Ti}-\mathrm{Nb}$ and Ti spontaneously formed an oxide film passivating the metallic surface in the saline solution. Nevertheless, in the case of the activated sample the TiN layer on the surface acts as the passive layer on this material $[23,27]$. This suggests that a protective passive film was quickly formed on $\mathrm{Ti}, \mathrm{Ti}-\mathrm{Nb}$ and Ti-Mo surfaces in saline solution, remaining stable after $1 \mathrm{~h}$ of immersion.

Although corrosion behaviour depends on several factors such as composition, environment or microstructure, similar behaviour and $\mathrm{E}_{\mathrm{oc}}$ values ( -205 to $-85 \mathrm{mV}$ vs. SCE) were found for CP-Ti and Ti-Nb alloys in artificial saliva [28].

Comparing $\mathrm{E}_{\mathrm{oc}}$ values, $\mathrm{Ti}-\mathrm{Nb}$ and $\mathrm{Ti}-\mathrm{Mo}_{\mathrm{NH} 4 \mathrm{Cl}}$ surfaces presented more positive values with respect to $\mathrm{Ti}$, indicating that the surface treatments performed seem to improve the protection characteristics of the spontaneous oxides formed. Similar behaviour was also reported for the $\beta$-type Ti-15Mo alloy which presented more positive OCP values compared to pure Ti or the $\alpha+\beta$ composition Ti-10Mo [29]. Therefore, this agrees with our OCP behaviour that suggests better corrosion 

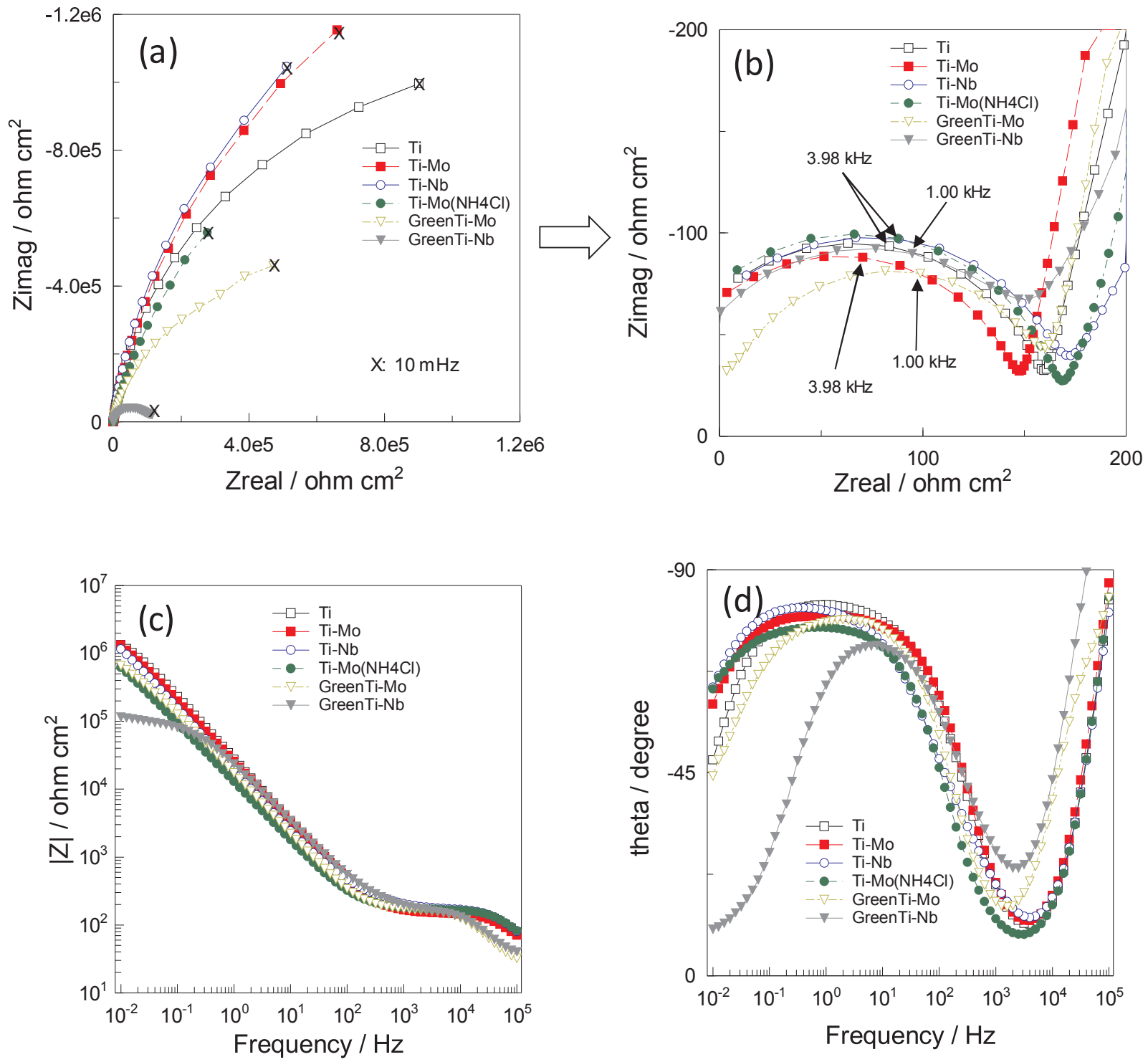

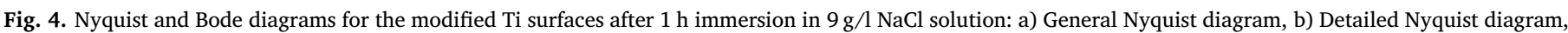
c) and d) Bode diagrams.

properties of our modified $\beta$-Ti surfaces.

Electrochemical impedance (EIS) measurements were performed to obtain electrochemical information of the modified Ti surfaces. Fig. 4 presents the Nyquist plots represented in the complex plane (the imaginary part versus the real part of the impedance vector) and Bode diagrams (impedance modulus and phase angle versus frequency represented in double-logarithmic and semi-logarithmic scales respectively) of the Ti surfaces measured after $1 \mathrm{~h}$ immersion in the saline solution.

Nyquist plots were all quite similar in shape, exhibiting one capacitive arc at high frequencies (HF) and an incomplete semicircle at low frequencies (LF). It can be observed that the Nyquist plots obtained for the Ti-Nb and Ti-Mo samples draw the LF semicircles of highest size while that of $\mathrm{Ti}-\mathrm{Mo}_{\mathrm{NH} 4 \mathrm{Cl}}$ was similar to $\mathrm{CP}-\mathrm{Ti}$, and those of GreenTi-Mo and GreenTi-Nb were smaller than CP-Ti. This indicates better corrosion behaviour of both $\mathrm{Ti}-\mathrm{Nb}$ and Ti-Mo materials with respect to CP-Ti and the green modified materials.

Regarding the Bode plots, it can be commented that its shape seems to be influenced by the performance of two well-differentiated time constants. This behaviour is typically ascribed to a porous passive layer with metal-electrolyte interactions due to the presence of pores on surface, and is common for passivating metals [14].

High impedance modulus values in the order of $10^{6} \Omega \mathrm{cm}^{2}$ were obtained for all the samples suggesting high corrosion resistance in the saline solution. However, this value was one order smaller in the case of GreenTi-Nb sample which could be attributed to the fact that the $\mathrm{Nb}$ deposition was performed on a green (as-pressed) Ti substrate. Both GreenTi-Nb and GreenTi-Mo materials were obtained through co-sintering and diffusion at the same stage, which led to a surface porosity 2.5\% higher than Ti-Nb and Ti-Mo samples that were obtained applying a diffusion treatment in a sintered Ti substrate. On the other hand, Ti$\mathrm{Mo}_{\mathrm{NH} 4 \mathrm{Cl}}$ sample processed by thermo-reactive diffusion presented similar behaviour to Ti since this material presents a TiN layer created by the activating agent $\left(\mathrm{NH}_{4} \mathrm{Cl}\right)$, which acts as a protective passive layer [30]. Impedance modulus values of the same order $10^{6} \Omega \mathrm{cm}^{2}$, and phase angle values ranging from 70 to $85^{\circ}$ were also reported in related $\beta$-type Ti-Nb-Mo alloys with different compositions and Ti-15Zr-10Nb at body temperature [14,31]. Furthermore, Nb presents low corrosion rate and passive regions even under fluoride solutions as reported by [32].

The impedance spectra were fitted with the equivalent circuit showed in Fig. 5 due to the information obtained from Nyquist and 


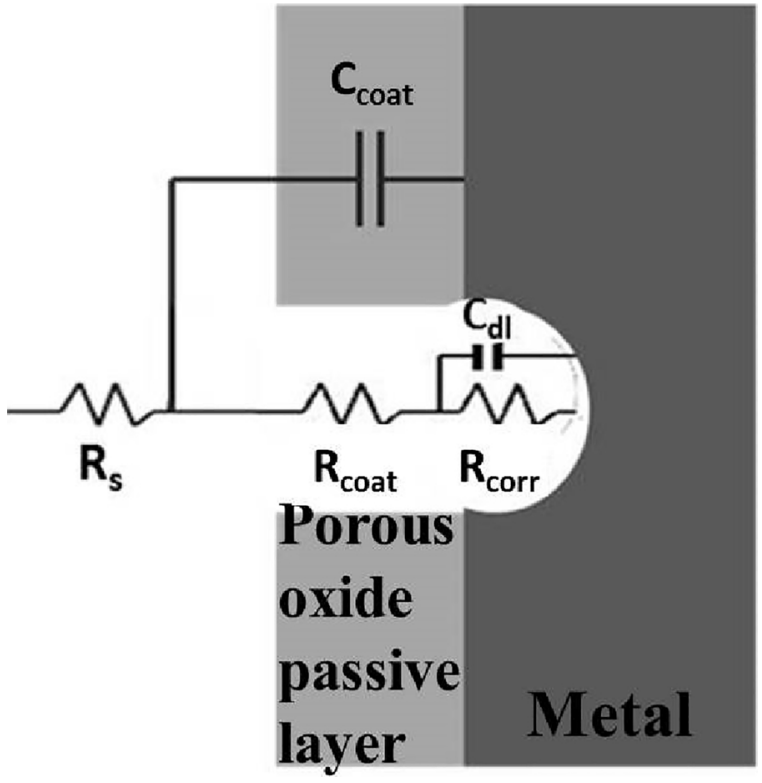

Fig. 5. Electric equivalent circuit used in the impedance spectra analysis based on a porous oxide passive layer model.

Bode plots. This equivalent circuit was previously used in a similar work in order to model the corrosion resistance of similar Ti alloys produced by powder metallurgy [33]. This equivalent circuit describes the behaviour of porous passive layers where the metal-electrolyte interactions take place into the layer's pores situated on the metal surfaces. In this circuit, $R_{s}$ represents the electrolyte resistance, $C_{\text {coat }}$ the coating capacitance, $R_{\text {coat }}$ the pore resistance of coating. Whereas $R_{\text {corr }}$ and $C_{d l}$ are associated to the corrosion resistance of the metal substrate and to the double layer capacitance at the metal-electrolyte interface, respectively, both of which take place at the base of pores and damaged areas developed in the treated-surface during the exposure to the saline solution.

In order to take into account the irregular characteristics of these surfaces, the capacitors of the selected equivalent circuit have been implemented by using Constant Phase Elements (CPEs) given by the equation below [34]:

$Z_{\mathrm{CPE}}=\frac{1}{Q(j \omega)^{\alpha}}$

where $j=\sqrt{ }-1, \omega$ is the angular frequency in $\operatorname{rad~s}^{-1}, \omega=2$ ??f, and $f$ is the frequency in Hz. The CPE is defined by two parameters $Q$ and $\alpha$, where $Q$ also named CPE-T has units of $\mathrm{s}^{\alpha} \Omega^{-1}$ or $\mathrm{F} \mathrm{s} \mathrm{s}^{\alpha-1}$ and $\alpha$ is a dimensionless number. $\alpha$ also known as CPE-P is related to a non-uniform current distribution due to the surface roughness or other distributed properties, and varies between 0 and 1 . The CPE reduces to a resistor for $\alpha=0$, to a Warburg element representing semi-infinite length diffusion phenomena for $\alpha=0.5$ and to an ideal capacitor for $\alpha=1$.

In the case of a parallel connection of a Constant Phase Elements CPE and a resistance $R$, the relationship between the capacitance $C$ and the associated CPE can be calculated by using [35]:

$C=\left(Q R^{(1-\alpha)}\right)^{1 / \alpha}$

Fig. 6 shows Nyquist and Bode plots representing the experimental and fitted data for GreenTi-Mo sample after $1 \mathrm{~h}$ of immersion in $9 \mathrm{~g} / \mathrm{l}$ $\mathrm{NaCl}$ solution, since all samples showed very similar behaviour (Fig. 4). As it can be seen, both fitted and experimental impedance spectra were very similar. Nevertheless, the last two points observed in the experimental Nyquist plot at the lowest frequencies were slightly deviated from the fitted plot and could be ascribed to the diffusion phenomena. The fitting result generally is accepted when the fitting $\chi^{2}$ parameter is smaller than $10^{-3}$. In our case, the good agreement between fitted and measured data can be appreciated in Fig. 6, and also confirmed by low errors and the small chi-squared value of $1.3 \times 10^{-3}$.

These results should be appreciated as a first approach due to some limitations found on the electrochemical measurements. On one hand, fitting the impedance plots at the lowest frequencies by using a finite element Warburg (Ws) was not possible due to the low number of impedance points that could be recorded in this frequency region. On the other hand, the higher diameter of the low frequency arc compared to that of the high frequency lead to an imprecise Rs value. This is occurs often due to the presence of artefacts which can come from improper electrode setup or instrumental limitations [36]. However, our results were not affected by these artefacts at high, middle and low frequencies, since all the equivalent circuit parameters $\left(\mathrm{R}_{\text {coat }}, \mathrm{C}_{\text {coat }}, \mathrm{C}_{d l} \mathrm{y}\right.$ $\mathrm{R}_{\text {corr }}$ ) were properly determined as are summarized in Table 2 after applying the equivalent circuit from Fig. 5.

Not very pronounced differences were observed between the bare $\mathrm{Ti}$ and the modified Ti surfaces, suggesting analogous dielectric properties. However, the passive layers formed on the different materials could show different corrosion behaviour due to the presence of $\mathrm{Nb}$ or Mo elements with different electrochemical reactivity features.

The high frequency region is associated to the dielectric properties of the diffusion layers created in this case by the $\mathrm{Nb}$ or Mo diffusion. $C_{\text {coat }}$ describes the dielectric "barrier" properties of these passive layers connected in parallel with $\mathrm{R}_{\text {coat }}$, which is associated to penetration of the electrolyte throughout the pores. All the samples showed $R_{\text {coat }}$ values around the same order. Ti-Nb sample exhibited a $R_{\text {coat }}$ value of 302 $\Omega \mathrm{cm}^{2}$ which was slightly higher than that of Ti sample $\left(261 \Omega \mathrm{cm}^{2}\right)$ indicating better corrosion resistance with higher anti-penetrating ability to electrolyte through the surface pores. Ti-Mo and $\mathrm{Ti}-\mathrm{Mo}_{\mathrm{NH} 4 \mathrm{Cl}}$ samples were in the same order similar to Ti and both GreenTi modified samples presented the lowest values. Concerning $C_{\text {coat }}$, $\mathrm{Ti}$ and $\mathrm{Ti}-\mathrm{Nb}$ samples presented capacitances an order of magnitude lower than the other tested samples which can be probably due to the higher porosity of the $\mathrm{Ti}$ and $\mathrm{Ti}-\mathrm{Nb}$ samples.

The medium frequency region is related with the charge-transfer, inversely proportional to the corrosion velocity of the metallic substrate in those areas where the electrolyte penetrated by the diffusion layer. CPE-T slightly increased one order for both of the modified GreenTi samples which may indicate a higher electrolyte penetration and higher degradation rate in comparison with the Ti-Mo, $\mathrm{Ti}-\mathrm{Mo}_{\mathrm{NH} 4 \mathrm{Cl}}$ and $\mathrm{Ti}$ samples. This supports that performing the Nb or Mo surface modification in Green Ti substrates leads to higher internal porosity than in sintered Ti substrates, leaving more conductive pathways for the electrolyte penetration. Finally, all $\alpha$ values were close to 1 , indicating the behaviour of a quasi-ideal capacitor.

According to literature, $\beta$-Ti alloys such as the Ti-15Zr-10Nb alloy present better electrochemical behaviour compared to Ti [31,37]. In our case, Ti-Nb and Ti-Mo surfaces also indicated better anticorrosive properties with respect to $\mathrm{Ti}$, since their passive layers have higher dielectric properties. Furthermore, comparing $\mathrm{Nb}$ and Mo additions, it has been found that Nb-containing alloys exhibited lower electron transfer and thus, high impedance values than Ti-Mo alloys [10]. In this context, our results from Fig. 3 are in agreement showing a very small difference but higher amplitude of the arc for Ti-Nb compared to Ti-Mo samples.

\subsection{Tribocorrosion behaviour}

The evolution of the coefficient of friction (COF) during sliding and the OCP before, during and after sliding is presented in Fig. 7. Since the modified green samples showed an electrochemical behaviour slightly lower than their respective modified sintered ones, the GreenTi-Mo material was discarded considering also to its lowest $R_{\text {coat }}$ value (Table 2).

COF values showed similar tendency between GreenTi-Nb, Ti-Nb 

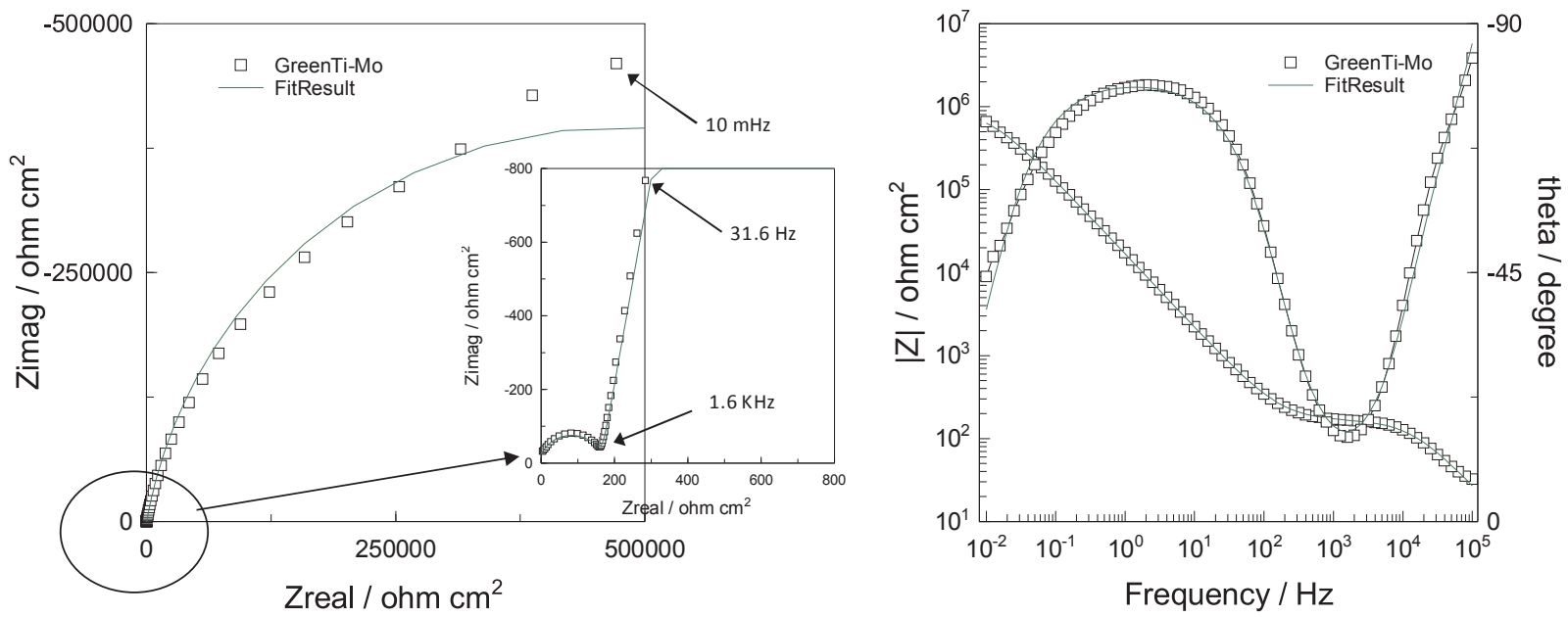

Fig. 6. Nyquist and Bode plots with fitting for GreenTi-Mo sample after $1 \mathrm{~h}$ of immersion in $9 \mathrm{~g} / \mathrm{l} \mathrm{NaCl} \mathrm{solution}$.

Table 2

Parameters of the equivalent circuit for the modified Ti samples after $1 \mathrm{~h} \mathrm{im-}$ mersed in $9 \mathrm{~g} / \mathrm{l} \mathrm{NaCl}$ solution.

\begin{tabular}{lllll}
\hline \multirow{2}{*}{ Materials } & \multicolumn{3}{l}{ Equivalent circuit parameters } \\
\cline { 2 - 5 } & CPE-T $\left(\mu \Omega^{-1} \mathrm{~cm}^{-2} \mathrm{~s}^{-\alpha 1}\right)$ & CPE-P $\left(\alpha_{1}\right)$ & $\begin{array}{l}\mathrm{R}_{\text {coat }} \\
(\Omega \mathrm{cm})^{2}\end{array}$ & $\begin{array}{l}\mathrm{C}_{\text {coat }} \\
\left(\mu \mathrm{F} \mathrm{cm}{ }^{-2}\right)\end{array}$ \\
\hline $\mathrm{Ti}$ & - & 0.84 & 261 & $9.23 \times 10^{-9}$ \\
$\mathrm{Ti}-\mathrm{Mo}$ & $7.31 \times 10^{-8}$ & 0.84 & 240 & $1.17 \times 10^{-8}$ \\
$\mathrm{Ti}-\mathrm{Nb}$ & $9.05 \times 10^{-8}$ & 0.78 & 302 & $7.36 \times 10^{-9}$ \\
Ti-Mo & $1.29 \times 10^{-7}$ & 0.89 & 247 & $1.13 \times 10^{-8}$ \\
GreenTi-Mo & $4.61 \times 10^{-8}$ & 0.92 & 182 & $6.98 \times 10^{-8}$ \\
GreenTi-Nb & $1.72 \times 10^{-7}$ & 0.90 & 215 & $5.43 \times 10^{-8}$ \\
\hline
\end{tabular}

and CP-Ti with a stable value around 0.45 . This may be attributed to the good lubricant properties of the $\mathrm{Nb}_{2} \mathrm{O}_{5}$ passive layer and the quick repassivation of $\mathrm{Nb}$ [4]. Ti-Mo also exhibited a stable COF value of 0.5 , while $\mathrm{COF}$ of $\mathrm{Ti}-\mathrm{Mo}_{\mathrm{NH} 4 \mathrm{Cl}}$ increased during sliding time from 0.2 to 0.65 . In the case of $\mathrm{Ti}-\mathrm{Mo}_{\mathrm{NH} 4 \mathrm{Cl}}$, the TiN layer created on surface by the activating agent $\left(\mathrm{NH}_{4} \mathrm{Cl}\right)$ during the thermo-reactive diffusion seems to lower the COF (0.2) initially. However, the increased COF values during sliding could be related to the increased roughness of the wear track through testing time. The highest hardness $(\approx 1025 \mathrm{HV})$ of the Ti$\mathrm{Mo}_{\mathrm{NH} 4 \mathrm{Cl}}$ surface with respect to rest of the modified surfaces (300-440 HV) lead to the formation of harder wear debris together with their accumulation on the surface increasing roughness and COF values.

Regarding OCP evolution, potentials were stable at similar values for all materials before sliding $(-0.1$ to $-0.25 \mathrm{~V})$. Then when sliding started, all samples showed an abrupt fall of the OCP usually attributed to the total or partial destruction of the different passive layers as a consequence of the mechanical action [38]. Under sliding, all modified Ti surfaces exhibited more positive potential values than CP-Ti, indicating lower tendency for corrosion on the modified surfaces. When the wear action was completed and the mechanical contact stopped, the repassivation phenomenon of the worn areas took place in all samples forming new barriers against corrosion [25,18]. Finally, potential reached higher values $(-0.1$ to $-0.35 \mathrm{~V})$ similar to those before sliding, indicating a great recovery capacity of the passive layers.

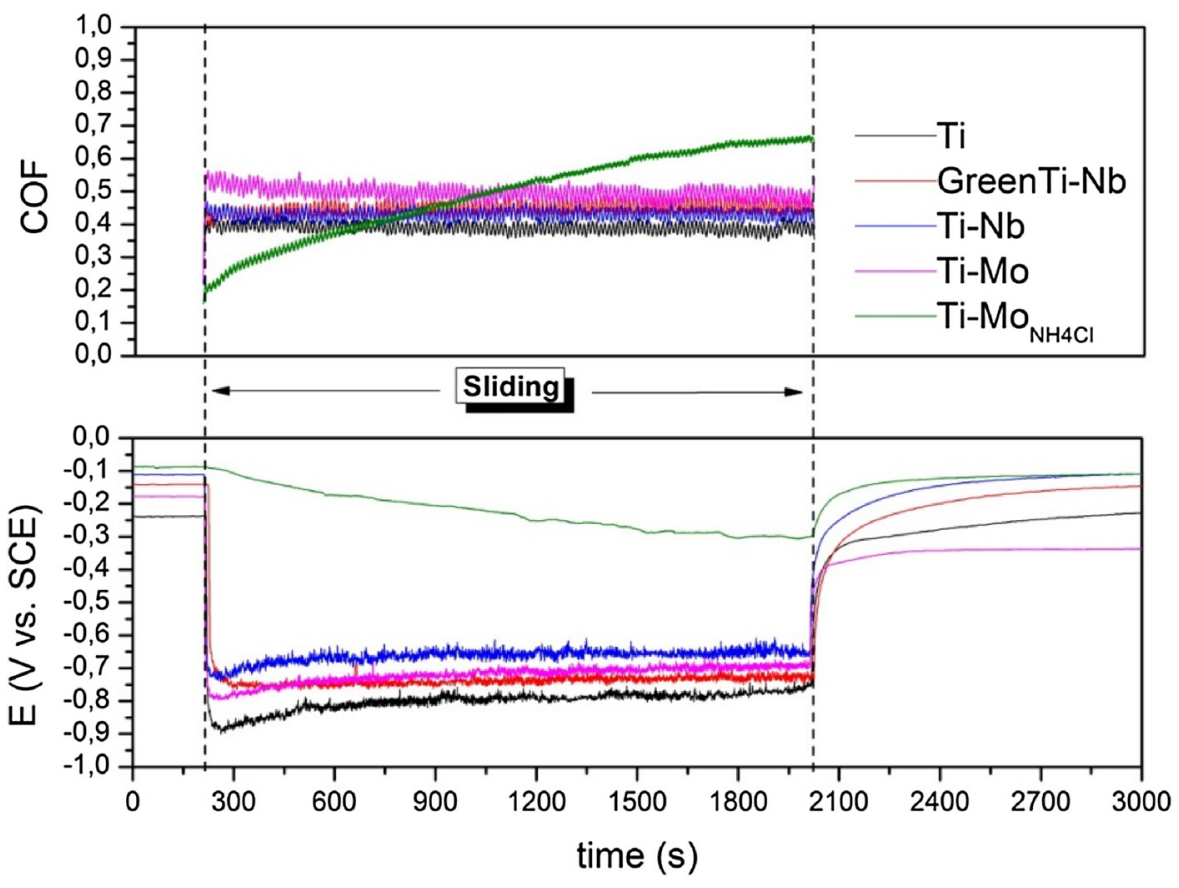

Fig. 7. Evolution of COF and OCP during tribocorrosion test in $9 \mathrm{~g} / 1 \mathrm{NaCl}$ solution. 
However, in the case of the Ti-Mo surface the OCP values were quite stable after 2250s and smaller than those before sliding, maybe suggesting a more severe damage on the surface. Other authors relate this behaviour to pitting corrosion phenomenon in HF solutions, since despite OCP values were almost recovered once sliding stopped, the surface of the materials was different from the initially surface due to the formation of wear scars and pores from pitting corrosion. These features could decrease the corrosion resistance of titanium surfaces as reported by [39]. Nevertheless, titanium surfaces present high corrosion resistance in $0.9 \% \mathrm{NaCl}$ solution, same as the electrolyte used in this study.

Generally, $\beta$-Ti alloys present a great recovery capacity of their oxide layers due to their good stability as was found by Ti-15Zr-7.5Mo [18]. However, different behaviour with potential values lower than those before sliding were found in other biological Ti-C-N coatings applied by physical vapour deposition on a Ti6Al4V alloy of similar surface hardness $8 \mathrm{GPa}$ to our Ti-Mo $\mathrm{NH}_{4 \mathrm{Cl}}$ material [40].

This behaviour is associated to the repassivation phenomenon of the metal surfaces. The repassivation rate for a certain period of time can be calculated by the formula below, where $\Delta \mathrm{E}(\mathrm{V})$ is stated as the potential variation, $\mathrm{t}(\mathrm{s})$ the time after interrupting sliding for which the repassivation rate, $\mathrm{k}_{1}$, is calculated; and $\mathrm{k}_{2}$ the constant determined by the solution where the abrasion of the material took place [41].

$\Delta \mathrm{E}=\mathrm{k}_{1} * \log \mathrm{t}+\mathrm{k}_{2}$

Fig. 8 shows the repassivation rate of all surfaces represented by means of $k_{1}$ constant values. Based on related investigations [42], the repassivation rate was calculated after $300 \mathrm{~s}$ sliding and 0.1 as $\mathrm{k}_{2}$ value, according to saline solution. It can be observed that both Ti-Nb surfaces presented the highest $k_{1}$ values together with the value of Ti sample. This is in agreement with the enthalpy formation of $\mathrm{Nb}$ with oxygen which is much higher than that of another elements such as $\mathrm{V}$ or $\mathrm{Al}$, making possible for the passive layer to stay longer and to repassivate quickly [4]. Hence, the repassivation rate was slightly reduced for TiMo samples with respect to Ti-Nb surfaces. The smallest $\mathrm{K}_{1}$ value of Ti$\mathrm{Mo}_{\mathrm{NH} 4 \mathrm{Cl}}$ sample could be attributed to the smaller recovery capacity of the TiN layer of this surface since nitride increased the surface hardness resulting in a less damaged surface.

Fig. 9 presents the SEM micrographs taken from the centre of the wear tracks representing the worn areas after tribocorrosion tests. On one hand, CP-Ti and the $\beta$-Ti surfaces GreenTi-Nb, Ti-Nb and Ti-Mo show evidence of grooves parallel to the sliding direction as signs of abrasive wear mechanism (Fig. 9a-d). Nevertheless, grooves observed on the Ti-Mo $\mathrm{NH}_{4 \mathrm{Cl}}$ surface (Fig. 9e) were much shallower with respect to the other surfaces due to its higher hardness and increased Young's modulus characteristic of the TiN layer on surface of this material. On the other hand, it can be clearly observed that this surface showed less plastic deformation compared to the other samples, having a narrow, smooth and shallow wear track up to three times smaller $(\approx 214 \mu \mathrm{m})$ with respect to $\mathrm{Ti}(\approx 643 \mu \mathrm{m})$. This is mainly attributed to the higher hardness leading to the reduction of plasticity. Thus, the noticeable increased hardness of the $\mathrm{Ti}-\mathrm{Mo}_{\mathrm{NH} 4 \mathrm{Cl}}$ led to improve the tribocorrosion behaviour. This agrees with the low COF value (0.2) observed for the

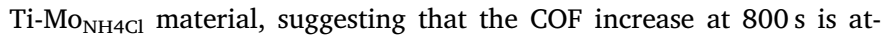
tributed to the mainly accumulation of harder wear debris. Although tribocorrosion studies in for comparable materials are less common in the literature, a Mo-N surface, similar in composition to our Ti-Mo $\mathrm{NH}_{4 \mathrm{Cl}}$, deposited by plasma on Ti-6Al-4 V was also found to wear less that the untreated alloy in dry conditions due to hardness [43].

Dark areas were noticed on all the modified surfaces, being more evident on the bare Ti surface. From the EDS analysis (Fig. 9f) the composition of these areas is given, which mainly contains $\mathrm{Ti}$ and $\mathrm{O}$ elements, corresponding to titanium oxides. Two different areas Z4 and $\mathrm{Z5}$, corresponding to darker zones and grey surface, respectively, were analysed on the Ti-Mo material with the aim of comparing composition qualitatively. This showed oxygen only in the darker areas (Z4), supporting the idea that these regions correspond to oxides, probably $\mathrm{TiO}_{2}$ and $\mathrm{MoO}_{3}$. The repetitive transfer of Ti between the sliding surfaces and its oxidation leads to the formation of oxidised wear debris and eventually their adhesion to the surface under the influence of the applied load. Hence, the wear mechanisms under synergistic interactions between wear and corrosion for all the surfaces were shown as a combination of abrasion by the presence of grooves, with some adhesive oxide areas due to oxides accumulation [44]. The surfaces showed similar wear abrasion mechanism, although GreenTi-Nb exhibited more abrasive grooves compared to $\mathrm{CP}-\mathrm{Ti}$, whereas $\mathrm{Ti}-\mathrm{Nb}$ and Ti-Mo presented less abrasion areas with respect to $\mathrm{Ti}$, and the $\mathrm{Ti}-\mathrm{Mo}_{\mathrm{NH} 4 \mathrm{Cl}}$ surface was practically not damaged. The adhesive oxide areas were mainly observed on CP-Ti.

When comparing the darker areas on Ti-Nb and Ti-Mo surfaces, it is worth noticing that they are more visible on the Ti-Mo surface (Fig. 9c) which qualitatively agrees with the oxygen found on this surface. This could be related to their slightly higher COF values during sliding with respect to $\mathrm{COF}$ of the Ti-Nb surface (Fig. 7), since the higher amount of oxide particles would lead to the COF increase of Ti-Mo surface.

Recently, similar conditions ( $2 \mathrm{~N}$ load, $1 \mathrm{~Hz}$ frequency, $6 \mathrm{~mm}$ alumina ball, and $8 \mathrm{~mm}$ stroke length) were used in a related investigation on the tribocorrosion behaviour of some $\beta$-Ti alloys [17]. They found that $(\alpha+\beta)$-Ti6Al4V and ( $\beta)$-Ti13Nb13Zr alloys presented the best tribocorrosion behaviour while ( $\beta$ )-Ti15Mo and ( $\beta$ )-Ti45Nb alloys exhibited easier plastic deformation. These authors attributed the lower elastic modulus of these alloys as the main cause affecting the tribocorrosion behaviour. Another common wear mechanism reported in

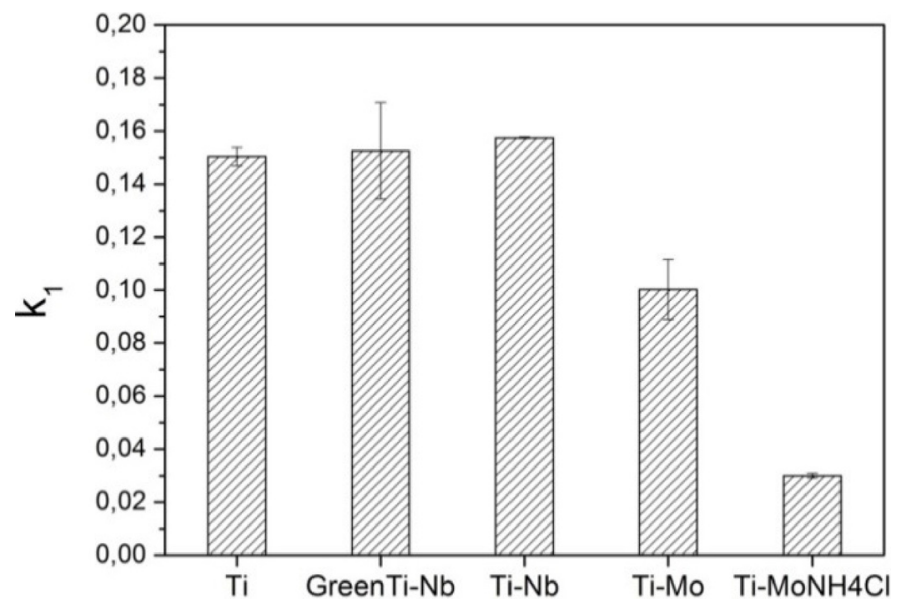

Fig. 8. Repassivation rate represented by constant $K_{1}$ values obtained from Eq. (3). 
a) $\mathrm{Ti}$

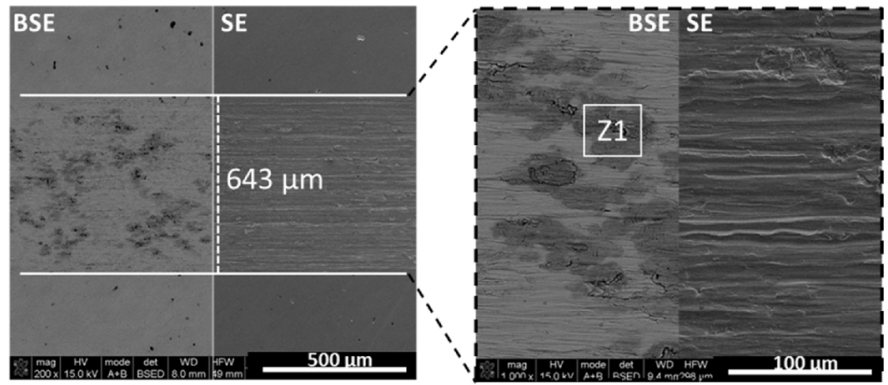

b) Green Ti-Nb

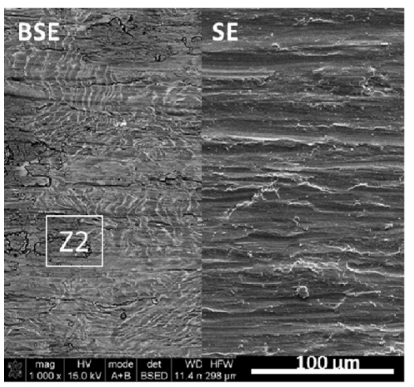

c) $\mathrm{Ti}-\mathrm{Nb}$

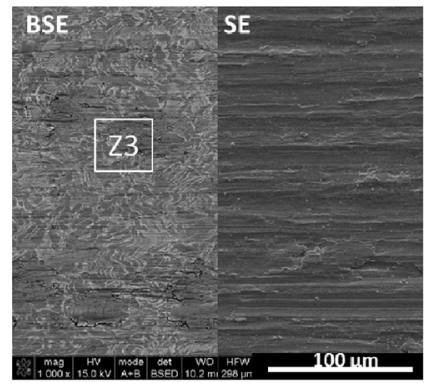

d) Ti-Mo

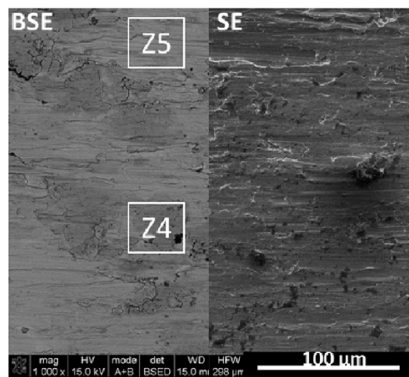

e) $\mathrm{Ti}-\mathrm{MoNH}_{4} \mathrm{Cl}$

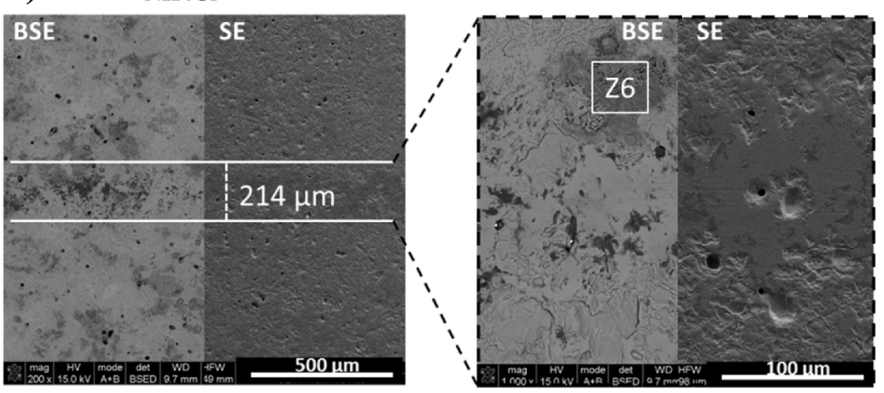

f)

\begin{tabular}{cccccc}
\hline Material & Marked areas & Ti [\%] & O [\%] & Nb [\%] & Mo [\%] \\
\hline Ti & Z1 & 97.35 & 2.65 & - & - \\
GreenTi-Nb & Z2 & 83.07 & 4.80 & 12.13 & - \\
Ti-Nb & Z3 & 84.90 & 2.61 & 12.49 & - \\
Ti-Mo & Z4 & 84.94 & 7.87 & - & 7.19 \\
& Z5 & 89.82 & - & - & 10.18 \\
Ti-Mo & Z6 & 87.01 & 12.99 & - & -
\end{tabular}

Fig. 9. Detailed BSE-SE images of the worn surfaces after tribocorrosion test, and EDS analysis taken from the marked areas.

tribocorrosion for this type of alloys is the three-body abrasion since $\beta$ Ti alloys in simulated body fluid could form hydroxyapatite on surface with the apparition of entrapped hydroxyapatite particles acting as three-body abrasion wear [16]. However, this study was conducted in saline solution, thus the abrasion mainly is due to wear debris but not because of hydroxyapatite particles formation. Actually, the tribocorrosion mechanisms in $\beta$-Ti alloys are still not fully understood although improved dry sliding wear behaviour is being achieved by similar surface treatments such as molybdenizing titanium alloys [45].

From the wear track analysis on the samples, the amount of wear volume was calculated following a model as detailed somewhere else [20]. Wear volume is an important issue in biomaterials since high wear volume is related to metallic ions release and adverse reactions in the body $[5,4]$. The average wear volume of the modified Ti materials remained around $8.51 \times 10^{-2} \mathrm{~mm}^{3}, \quad 6.54 \times 10^{-2} \mathrm{~mm}^{3}$, $7.28 \times 10^{-2} \mathrm{~mm}^{3}$ and $1.29 \times 10^{-3} \mathrm{~mm}^{3}$ for GreenTi-Nb, Ti-Nb, Ti-Mo and $\mathrm{Ti}-\mathrm{Mo}_{\mathrm{NH} 4 \mathrm{Cl}}$, respectively; with respect to $6.04 \times 10^{-2} \mathrm{~mm}^{3}$ of $\mathrm{CP}$ $\mathrm{Ti}$. Whereas $\mathrm{Ti}$ and $\mathrm{Ti}-\mathrm{Nb}$ exhibited similar results, GreenTi-Nb presented slightly higher wear volume probably associated to the deeper grooves of abrasion. Nonetheless, very low wear volume was noticed for $\mathrm{Ti}^{-\mathrm{Mo}_{\mathrm{NH} 4 \mathrm{Cl}}}$ surface, being related to the high hardness. These results suggest that when the surface modification is carried out in GreenTi (aspressed) during the one single step co-sintering and diffusion route, wear resistance seems to be less than when $\mathrm{Nb}$ diffusion in performed in a sintered Ti substrate. Nevertheless, the tendency for corrosion under synergistic wear-corrosion interactions seems to not be affected by this difference, since both Ti-Nb materials showed stable OCP values higher than CP-Ti. This wear dependence on diffusion treatments could be ascribed to hardness, since high hardness is related to the reduction of plasticity. In this context, although hardness values are in the same order, Ti-Nb presents $320 \mathrm{HV}$ with respect to $280 \mathrm{HV}$ of GreenTi-Nb [24]. This is in agreement with the deeper grooves observed on the GreenTi-Nb material compared to those on Ti-Nb. However regarding corrosion, it has been shown that the Nb diffusion in both Ti substrates (green or sintered) lowers the tendency for corrosion with respect to $\mathrm{Ti}$. The improvement on the corrosion resistance of $\mathrm{Ti}$ is mainly related to the excellent electrochemical behaviour of the $\mathrm{Nb}_{2} \mathrm{O}_{5}$ oxide formed.

The dry sliding wear behaviour of these modified Ti materials was 
recently studied and reported in our previous work [20], under different conditions of counter material, load and stroke length. An improvement on wear resistance in dry sliding conditions was achieved for all the modified Ti surfaces. With the same testing conditions that those employed in this investigation, wear volume in the order of $10^{-2} \mathrm{~mm}^{3}$ and $10^{-3} \mathrm{~mm}^{3}$ was obtained for the $\beta$-surfaces (Ti-Nb and Ti$\mathrm{Mo}$ ) and the activated material $\mathrm{Ti}-\mathrm{Mo}_{\mathrm{NH} 4 \mathrm{Cl}}$, respectively, showing wear rate values between 53-96 \% lower with respect to CP-Ti. Therefore, from the present study it could be stated that under the synergistic effect of wear-corrosion these new diffusion-based powder metallurgy Ti surfaces (GreenTi-Nb, Ti-Nb and Ti-Mo) designed by thermo-chemical treatments exhibit higher wear resistance with respect to dry sliding wear, and the saline solution has an aggressive effect on the materials surface during wear. However, Ti-Mo $\mathrm{NH}_{4 \mathrm{Cl}}$ surface showed similar wear tendency in both cases, presenting interesting tribocorrosion properties with high corrosion and wear resistance.

Another interesting issue derived from this investigation related to corrosion was that, while only Ti-Nb and Ti-Mo obtained by diffusion in sintered $\mathrm{Ti}$ substrate and $\mathrm{Ti}-\mathrm{Mo}_{\mathrm{NH} 4 \mathrm{Cl}}$ by thermo-reactive diffusion presented high corrosion resistance, similar to CP-Ti during static conditions, the corrosion tendency under wear-corrosion synergism was lower than that of the CP-Ti for all the treated-surfaces included GreenTi-Mo and GreenTi-Nb. This means that all the treated-surfaces show a better anticorrosive properties when a mechanical action starts to take place on their surfaces.

\section{Conclusions}

Corrosion and tribocorrosion behaviour of Ti-Nb and Ti-Mo surfaces composed of a microstructural gradient $(\beta / \alpha+\beta / \alpha)$ was evaluated in $9 \mathrm{~g} / \mathrm{l} \mathrm{NaCl}$ solution and compared to that of the ( $\alpha$-single phase) $\mathrm{CP}$ Ti obtained through powder metallurgy. After electrochemical and tribocorrosion characterization, the main conclusions can be summarized as:

i) Regarding corrosion behaviour, Ti-Nb and Ti-Mo surfaces exhibited better anticorrosive properties than either $\mathrm{CP}-\mathrm{Ti}$ or the surfaces GreenTi-Nb and GreenTi-Mo (obtained through co-sintering and diffusion in a one single step).

ii) All the modified $\mathrm{Ti}$ surfaces presented impedance modulus approximately around $10^{5}-10^{6} \Omega$ at low frequencies. These high impedance values can be attributed to a high corrosion resistance performance; suggesting no deterioration of Ti corrosion resistance.

iii) Under synergistic wear-corrosion action, the modified Ti samples indicated similar COF (0.45) and lower tendency for corrosion compared to CP-Ti. Regarding COF, the Ti-Mo surface exhibited slightly higher mean values $(0.5)$ than $\mathrm{Ti}-\mathrm{Nb}(0.45)$ while $\mathrm{COF}$ of $\mathrm{Ti}-$ $\mathrm{Mo}_{\mathrm{NH} 4 \mathrm{Cl}}$ was initially lower $(0.2)$ increasing during sliding time to 0.65 .

iv) $\mathrm{Nb}$ diffusion in titanium increased repassivation rate in both $\mathrm{Ti}-\mathrm{Nb}$ and GreenTi-Nb surfaces. On the other hand, the molybdenum nitride surface $\left(\mathrm{Ti}^{-} \mathrm{Mo}_{\mathrm{NH} 4 \mathrm{Cl}}\right)$ presented the best tribocorrosion resistance with the lowest tendency for corrosion and the minimum wear volume $\left(1.29 \times 10^{-3} \mathrm{~mm}^{3}\right)$. A combination of abrasion with adhesive oxide areas was presented on all the samples. However, abrasion was smoother on Ti-Nb surface, and highly reduced on Ti$\mathrm{Mo}_{\mathrm{NH} 4 \mathrm{Cl}}$.

In this first approach to the corrosion and tribocorrosion behaviour of these new $\mathrm{Ti}-\mathrm{Nb}$, Ti-Mo and $\mathrm{Ti}-\mathrm{Mo}_{\mathrm{NH} 4 \mathrm{Cl}}$ diffusion-based titanium surfaces designed for biomaterials, positive results in terms of both static corrosion and corrosion under wear action have been demonstrated. However, although the Ti-Mo $\mathrm{NH}_{\mathrm{N} 4 \mathrm{Cl}}$ surface exhibited a clear improvement on the tribocorrosion resistance, further studies employing conditions closer to physiological medium with proteins or bioorganisms, different loading or $\mathrm{pH}$ and metal ion release quantification should be carried out in future works to have a better understanding to the tribocorrosion behaviour.

\section{Acknowledgments}

The authors would like to thank the funding provided for this research by the Regional Government of Madrid (program MULTIMATCHALLENGE-CM, ref. S2013/MIT-2862), the Spanish Government through the Ramón y Cajal contract RYC-2014-15014 and by the Institute of Alvaro Alonso Barba (IAAB) of the University Carlos III of Madrid for the research stay of two months in CMEMS-UMINHO (University of Minho). This study was partially supported by FCT with the reference project UID/EEA/04436/2013, by FEDER funds through the COMPETE 2020 - Programa Operacional Competitividade e Internacionalização (POCI) with the reference project POCI-01-0145FEDER-006941.

\section{References}

[1] S.J.L. Sullivan, L.D.T. Topoleski, Surface modifications for improved wear performance in artificial joints: a review, Miner. Met. Mater. Soc. 67 (11) (2015) 2502-2517.

[2] R.I.M. Asri, et al., Corrosion and surface modification on biocompatible metals: a review, Mater. Sci. Eng. C 77 (2017) 1261-1274.

[3] M.T. Mohammed, Z.A. Khan, A.N. Siddiquee, Surface modifications of titanium materials for developing corrosion behavior in human body environment: a review, Procedia Mater. Sci. 6 (Icmpc) (2014) 1610-1618.

[4] M. Geetha, a.K. Singh, R. Asokamani, a.K. Gogia, Ti based biomaterials, the ultimate choice for orthopaedic implants - a review, Prog. Mater. Sci. 54 (no. 3) (2009) $397-425$

[5] L. Kunčická, R. Kocich, T.C. Lowe, Advances in metals and alloys for joint replacement, Prog. Mater. Sci. (April) (2017).

[6] M. Hussein, A. Mohammed, N. Al-Aqeeli, Wear characteristics of metallic biomaterials: a review, Mater. (Basel) 8 (5) (2015) 749-2768.

[7] N.S. Manam, et al., Study of corrosion in biocompatible metals for implants: a review, J. Alloys Compd. 701 (2017) 698-715.

[8] J.M. Calderon Moreno, et al., Surface analysis and electrochemical behavior of Ti20Zr alloy in simulated physiological fluids, Mater. Sci. Eng. B Solid-State Mater. Adv. Technol. 178 (18) (2013) 1195-1204.

[9] J.C.M. Souza, M. Henriques, W. Teughels, P. Ponthiaux, J.-P. Celis, L.A. Rocha, Wear and corrosion interactions on titanium in oral environment: literature review, J. Biol. Tribo-Corros. 1 (3) (2015).

[10] A. Revathi, et al., Current advances in enhancement of wear and corrosion resistance of titanium alloys - a review, Mater. Technol. 7857 (2016), http://dx.doi. org $/ 10.1080 / 10667857.2016 .1212780$.

[11] A.K. Shukla, R. Balasubramaniam, S. Bhargava, Properties of passive film formed on CP titanium, Ti-6Al-4V and Ti-13.4Al-29Nb alloys in simulated human body conditions, Intermetallics 13 (2005) 631-637.

[12] M.Z. Ibrahim, A.A.D. Sarhan, F. Yusuf, M. Hamdi, Biomedical materials and techniques to improve the tribological, mechanical and biomedical properties of orthopedic implants - a review article, J. Alloys Compd. 714 (2017) 636-667.

[13] R. Olivares-navarrete, J.J. Olaya, C. Ramírez, Biocompatibility of niobium coatings, Coatings 1 (2011) 72-87.

[14] R. Chelariu, et al., Metastable beta Ti-Nb-Mo alloys with improved corrosion resistance in saline solution, Electrochim. Acta 137 (2014) 280-289.

[15] J.C.M. Souza, M. Henriques, R. Oliveira, W. Teughels, J.-P. Celis, L.A. Rocha, Biofilms inducing ultra-low friction on titanium, J. Dent. Res. 89 (12) (2010) 1470-1475.

[16] X. Yang, C.R. Hutchinson, Corrosion-wear of b-Ti alloy TMZF (Ti-12Mo-6Zr-2Fe) in simulated body fluid, Acta Biomater. 42 (2016) 429-439.

[17] I. Hacisalihoglu, A. Samancioglu, F. Yildiz, G. Purcek, A. Alsaran, Tribocorrosion properties of different type titanium alloys in simulated body fluid, Wear 332-333 (2014).

[18] D.R.N. Correa, P.A.B. Kuroda, C.R. Grandini, L.A. Rocha, F.G.M. Oliveira, Tribocorrosion behavior of $\beta$-type Ti-15Zr-based alloys, Mater. Lett. 179 (2016) 118-121.

[19] A. Fan, L. Qin, L. Tian, B. Tang, Corrosion resistance of molybdenum nitride modified Ti6Al4V alloy in $\mathrm{HCl}$ solution, J. Wuhan Univ. Technol. Mater. Sci. Ed. 23 (3) (2008) 358-361.

[20] J. Ureña, E. Tabares, S. Tsipas, A. Jiménez-Morales, E. Gordo, Dry sliding wear behaviour of $\beta$-type Ti-Nb and Ti-Mo surfaces designed by diffusion treatments for biomedical applications, J. Mech. Behav. Biomed. Mater. (2018) p. accepted.

[21] J. Ureña, S.A. Tsipas, A. Jiménez-Morales, E. Gordo, R. Detsch, A.R. Boccaccini, Invitro study of the bioactivity and cytotoxicity response of Ti surfaces modified by $\mathrm{Nb}$ and Mo diffusion treatments, Surf. Coat. Technol. 335 (2018) 148-158.

[22] J. Ureña, S. Tsipas, A. Jiménez-morales, E. Gordo, R. Detsch, A.R. Boccaccini, Cellular behaviour of bone marrow stromal cells on modified Ti-Nb surfaces, Mater. Des. 140 (2018) 452-459.

[23] J. Ureña, et al., Surface modification of powder metallurgy titanium by colloidal techniques and diffusion processes for biomedical applications, Adv. Eng. Mater. 19 
(6) (2016) 1600207

[24] J. Ureña, et al., Role of beta-stabilizer elements in microstructure and mechanical properties evolution of PM modified Ti surfaces designed for biomedical applications, Powder Metall. 61 (2) (2018) 90-99.

[25] Z. Doni, A.C. Alves, F. Toptan, L.A. Rocha, M. Buciumeanu, Tribocorrosion behaviour of hot pressed CoCrMo-HAP biocomposites, Tribol. Int. 91 (2015) 221-227.

[26] F. Toptan, a.C. Alves, I. Kerti, E. Ariza, La. Rocha, Corrosion and tribocorrosion behaviour of Al-Si-Cu-Mg alloy and its composites reinforced with B4C particles in $0.05 \mathrm{M} \mathrm{NaCl}$ solution, Wear 306 (1-2) (2013) 27-35.

[27] S.A. Tsipas, E. Gordo, Molybdeno-aluminizing of powder metallurgy and wrought Ti and Ti-6Al-4V alloys by pack cementation process, Mater. Charact. 118 (2016) 494-504.

[28] Z. Cai, T. Shafer, I. Watanabe, M.E. Nunn, T. Okabe, Electrochemical characterization of cast titanium alloys, Biomaterials 24 (2003) 213-218.

[29] N.T.C. Oliveira, a.C. Guastaldi, Electrochemical stability and corrosion resistance of Ti-Mo alloys for biomedical applications, Acta Biomater. 5 (1) (2009) 399-405.

[30] S.A. Tsipas, E. Gordo, A. Jiménez-Morales, Oxidation and corrosion protection by halide treatment of powder metallurgy Ti and Ti6Al4V alloy, Corros. Sci. 88 (2014) 263-274.

[31] J.M. Calderon-Moreno, et al., Microstructural and mechanical properties, surface and electrochemical characterisation of a new Ti-Zr-Nb alloy for implant applications, J. Alloys Compd. 612 (2014) 398-410.

[32] J.X. Yu Li, Is niobium more corrosion-resistant than commercially pure titanium in fluoride-containing artificial saliva? Electrochim. Acta 233 (April (10)) (2017) $151-166$.

[33] J. Ureña, E. Gordo, E.M. Ruiz-Navas, N. Vilaboa, L. Saldaña, A. Jiménez-Morales, Electrochemical comparative study on corrosion behavior of conventional and powder metallurgy titanium alloys in physiological conditions, Met. Powder Rep. 72 (2) (2017) 118-123.

[34] L. Diaz, F.R. García-Galvan, I. Llorente, A. Jiménez-Morales, J.C. Galván, F Jr., Effect of heat treatment of magnesium alloy substrates on corrosion resistance of a hybrid organic-inorganic sol-gel film, RSC Adv. 5 (2015) 105735-105746.
[35] M.E. Orazem, B. Tribollet, V. Vivier, D.P. Riemer, E. White, A. Bunge, On the use of the power-law model for interpreting constant-phase-element parameters, J. Braz. Chem. Soc. 25 (3) (2014) 532-539.

[36] F. La Mantia, A. Battistel, M. Fan, J. Stojadinovi, Analysis and mitigation of the artefacts in electrochemical impedance spectroscopy due to three-electrode geometry, Electrochim. Acta 135 (2014) 133-138.

[37] H. Mi-Kyung, K. Jai-Youl, H. Moon-Jin, S. Ho-Jun, P. Yeong-Joon, Effect of Nb on the microstructure, mechanical properties, corrosion behavior, and cytotoxicity of Ti-Nb alloys, Materials (Basel) 8 (2015) 5986-6003.

[38] Z. Doni, et al., Dry sliding and tribocorrosion behaviour of hot pressed CoCrMo biomedical alloy as compared with the cast CoCrMo and Ti6Al4V alloys, Mater. Des. 52 (2013) 47-57.

[39] J.C.M. Souza, S.L. Barbosa, E. Ariza, J.-P. Celis, L.A. Rocha, Simultaneous degradation by corrosion and wear of titanium in artificial saliva containing fluorides, Wear 292-293 (2012) 82-88.

[40] D. Viteri, G. Barandika, R. Bayo, V. Sa, J.E. Moreno, C. Pe, Development of Ti-C-N coatings with improved tribological behavior and antibacterial properties, J. Mech. Behav. Biomed. Mater. 55 (2016) 75-86.

[41] F. Contu, B. Elsener, A study of the potentials achieved during mechanical abrasion and the repassivation rate of titanium and Ti6Al4V in inorganic buffer solutions and bovine serum, Electrochim. Acta 50 (2004) 33-41.

[42] T. Hanawa, K. Asami, K. Asaoka, Repassivation of titanium and surface oxide film regenerated in simulated bioliquid, J. Biomed. Mater. Res, 40 (1998) 530-538.

[43] B. Tang, P.-Q. Wu, X.-Y. Li, A.-L. Fan, Z. Xu, J.-P. Celis, Tribological behavior of plasma Mo-N surface modified Ti-6Al-4V alloy, Surf. Coat. Technol. 179 (2-3) (2004) 333-339.

[44] D. Landolt, S. Mischler, Tribocorrosion of Passive Metals and Coatings, ISBN: 978-184569-966-6 (2011).

[45] W.P. Liang, Q. Miao, N.J. Ben, B.L. Ren, Tribological behaviors of Ti-6Al-4V alloy with surface plasma molybdenized layer, Surf. Coat. Technol. 228 (Suppl.1) (2013) S249-S253. 